\title{
Onychomycosis Case Developing during Interferon Treatment
}

Dear Editor,

Interferons (IFNs) are used in the treatment of hepatitis $B$ and hepatitis $C$ infections. However, side effects related to the treatment can create substantial problems (1).

The cutaneous side effects include dermatitis, hyperpigmentation, malar erythema, prurigo, acantholytic dermatosis, eczema, diffuse hypertricosis, vitiligo and alopecia (2). IFNs affect $\mathrm{T}$ lymphocyte behavior due to immunomodulatory effects and it is believed that they cause development of skin lesions through negative and abnormal $\mathrm{T}$ cell responses due to simple stimulations (3).

Our patient was a 45-year old male who had been suffering with (chronic hepatitis B) CHB for 10 years. He was suffering from flask paralysis in the lower extremity related to a Polio vaccine. His test results were as follows: Hepatitis surface antigen (HBsAg) positive, HBe antigen negative, Anti HBe positive, ALT: 25 U/L AST: 28 U/L HBV DNA: $5396 \mathrm{IU} / \mathrm{mL}$. The Histological Activity Index (HAl) was found to be 6/18. Fibrosis score was $1 / 6$ in his liver biopsy. Pegylated IFN alpha 2a $180 \mathrm{mcg} /$ week treatment was started for CHB therapy.

No side effects other than some simple neuropsychiatric side effects were encountered at the beginning of the treatment. Onychomycosis located in his toenails was found during the 6th week of treatment (Figure 1). It was found to be distal subungal onychomycozis. Sabouraud medium culture was obtained from the nail and aspergillus fumigatus multiplied in the medium after 1 week (Figure 2). Local antifungal treatment with $28 \%$ thioconazole solution $2 \times 1$ was prescribed for the disease, but a sufficient response was not achieved with this treatment. It was not possible to treat the patient suffering from $\mathrm{CHB}$ infection with systemic antifungals due to hepatotoxic effects. Hepatitis B IFN treatment of the patient showing virologic response was interrupted in the 48th week. Significant regression in onychomycosis was observed after interruption of the treatment. The onychomycosis encountered in the toenails of the patient, who was no longer treated with antifungal treatment, was entirely regressed during the $6^{\text {th }}$ month after interruption of IFN treatment (Figure 3 ).

IFN side effects affect patient adaptation during $\mathrm{CHB}$ treatment and treatment is sometimes interrupted due to these side effects. Side effects encountered in the skin are usually slight and dosage reduction is sufficient. Cutaneous side effects requiring medication to be stopped have been reported to occur at a rate of 6 to 14\% (4). The most common cutaneous side effects observed during IFN treatment are eczematous lesions (5). The majority of the side effects caused by IFNs are due to their effects on the immune system. Increasing lymphocyte cytotoxicity, $\mathrm{MHC}$ class I antigen expression and production of proinflammatory cytokines and stimulating differentiation of antigen presenting cells are among the immunological side effects of IFNs. IFNs stimulate cellular immunity by inducing activation of $\mathrm{T}$ hepler 1 cells and inhibiting $T$ helper 2 cells. IFN-gamma stimulates interleukin I and interleukin II synthesis $(2,4,6)$. Skin lesions are the natural result of the ability of IFNs to affect $T$ cell functions as well as cytokine attacks, such as IFN gamma, IL-1 and IL-2 (4). In the study conducted by Koga et al. (7), tinea unguium was related to lymphocyte proliferation and an increase in IFNgamma production in peripheral mononuclear cells. Skin lesions in dermatophytosis are associated with a Th1 response, which is characterized by an IFN-gamma response. This is a defence reaction of the skin against dermatomycosis. High levels of IFNgamma are produced as a result of the delayed type extreme stimulation reaction against dermatophyte antigens in dermatophytosis (8).

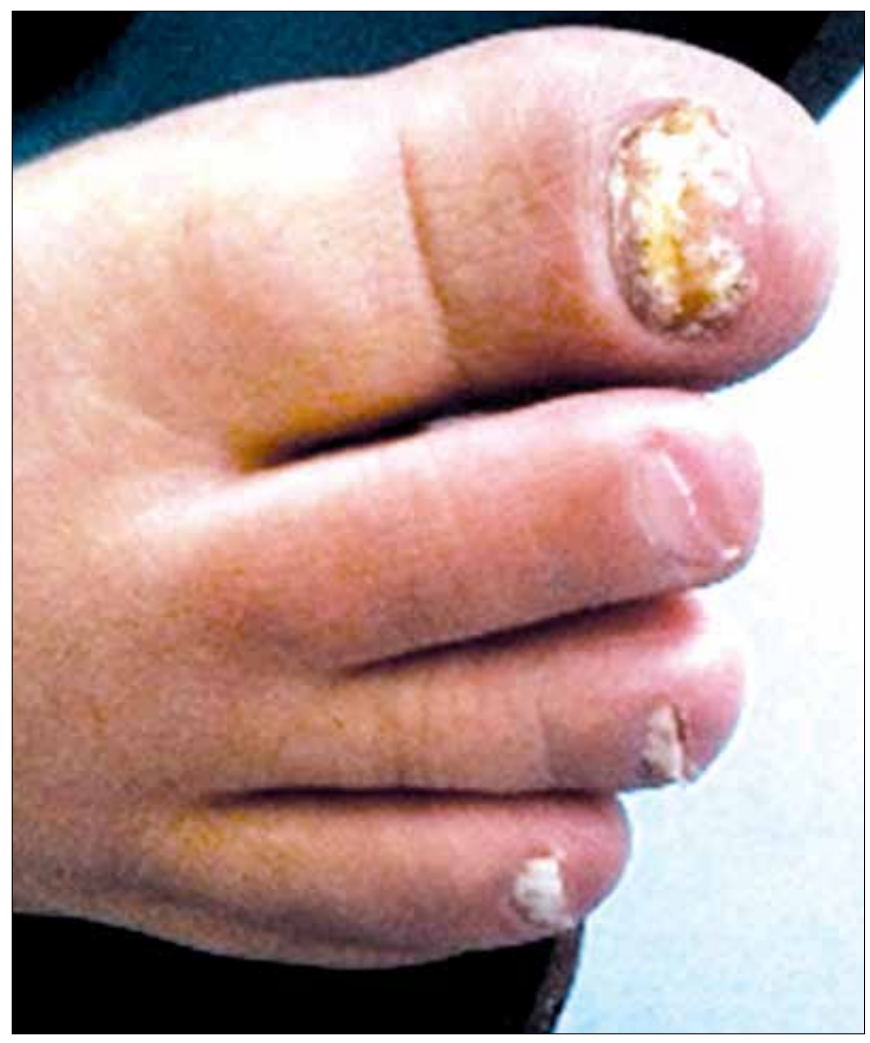

Figure 1. Onycomycosis appearance on the interferon therapy 


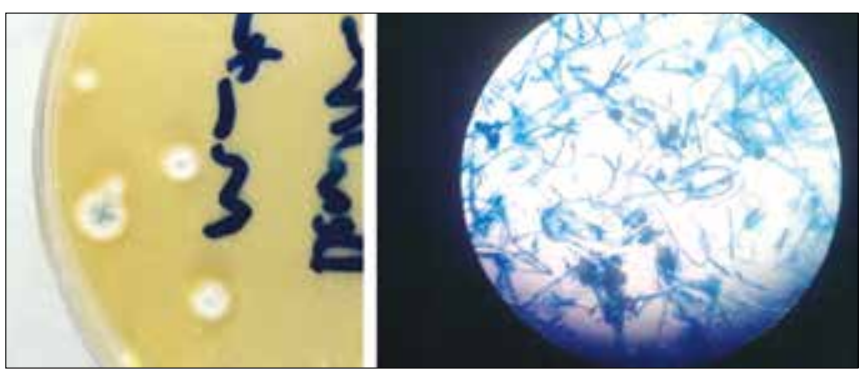

Figure 2. Aspergillus spp. was isolated in nail culture

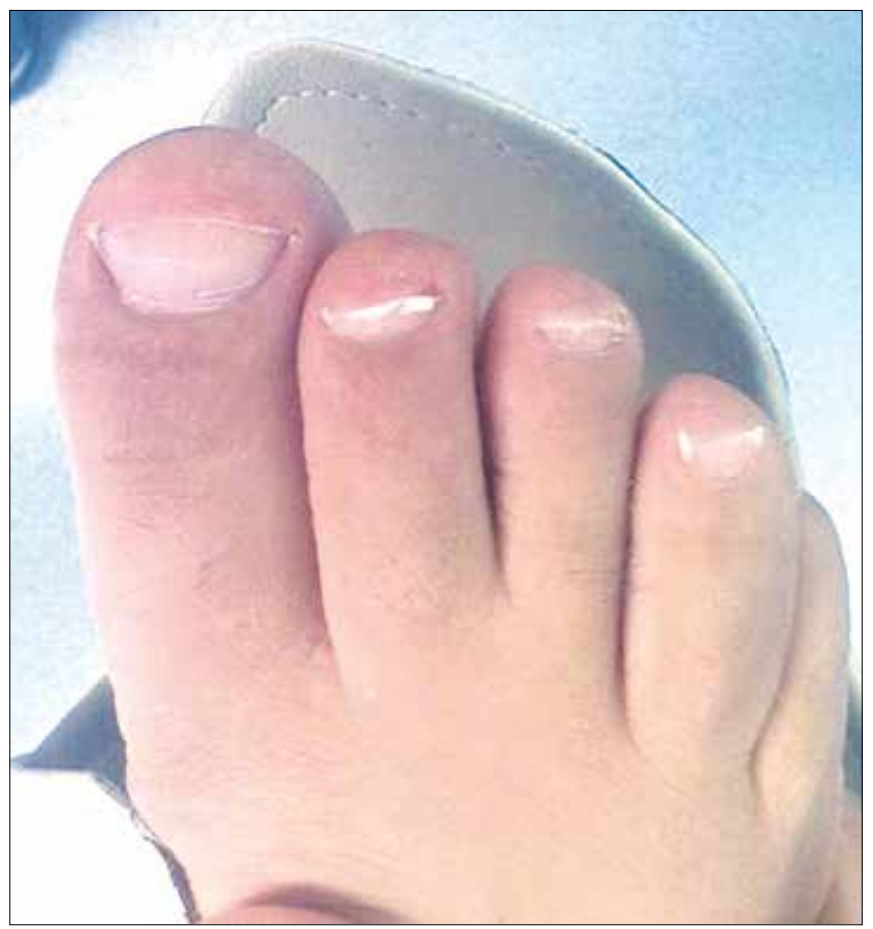

Figure 3. Six months after discontinuation of therapy

There is a correlation between the number of CD4 T cells and the appearance of onychomycosis. Proximal white subungual onychomycosis is a classic nail indication of AIDS. The onychomycosis observed in the toenails of our patient was distal subungual onychomycosis. Distal subungal onychomycosis is the most common clinical type of onychomycosis. It is established by dermatophytes at a rate of $99 \%$; tinea rubrum is the most common factor. The disease frequently begins with dermatophytosis alone. Subungual hyperkeratosis develops as a result of an attempt made by the toenail fold to defend itself and this hyperkeratosis progresses to proximal (9). Aspergillus fumigatus seldom causes onychomycosis. A. fumigatus was reported to be the dominant agent for onychomycosis for the first time in 1968 (10). Cutaneous aspergillus is observed in immune compromised patients, such as cancer patients, patients with solid organ transplanst and patients suffering from burns, who are particularly subject to significant doses of steroids (11).

We found no literature regarding onychomycosis developing during IFN treatment when a literature screen was performed. We believe that this situation is not rare, but we have found no publications regarding this subject issued up to now.

\section{Nazan Tuna1, Mustafa Teoman Erdem², Oğuz Karabay ${ }^{1}$ ${ }^{1}$ Department of Infectious Diseases and Clinical Microbiology, Sakarya Education and Research Hospital, Sakarya University, Sakarya, Turkey ${ }^{2}$ Department of Dermatology, Faculty of Medicine, Sakarya University, Sakarya, Turkey}

Informed Consent: Informed consent was obtained from patients who participated in this study.

\section{References}

1. Kwon H, Lok AS. Hepatitis B therapy. Nat Rev Gastroenterol Hepatol 2011:8:275-84.

2. Chang LW, Liranzo M, Bergfeld WF. Cutaneous side effects associated with interferon alpha therapy:a review. Cutis 1995;56:144.

3. Dereure O, Raison-Peyron N, Larrey D, Blanc F, Guilhou JJ. Diffuse inflammatory lesions in patients treated with interferon alfa and ribavirin for hepatitis C:a series of 20 patients. $\mathrm{Br} \mathrm{J}$ Dermatol 2002;147:1142-6. [CrossRef]

4. Kartal ED, Colak H, Ozgunes I, Usluer G. Exacerbation of psoriasis due to peginterferon alpha-2b plus ribavirin treatment of chronic active hepatitis C. Chemotherapy 2005;51:167-9. [CrossRef]

5. Vázquez-López F, Manjón-Haces JA, Pérez-Alvarez R, Pérez-Oliva $\mathrm{N}$. Eczema-like lesions and disruption of therapy in patients treated with interferon-alfa and ribavirin for chronic hepatitis $\mathrm{C}$ :the value of an interdisciplinary assessment. $\mathrm{Br} \mathrm{J}$ Dermatol 2004;150:1046-7. [CrossRef]

6. Kartal ED, Alpat SN, Ozgunes I, Usluer G. Reversible alopecia universalis secondary to PEG-interferon alpha- $2 b$ and ribavirin combination therapy in a patient with chronic hepatitis $C$ virus infection. Eur J Gastroenterol Hepatol 2007;19:817-20. [CrossRef]

7. Koga T, Shimizu A, Nakayama J. Interferon-gamma production in peripheral lymphocytes of patients with tinea pedis:comparison of patients with and without tinea unguium. Med Mycol 2001;39:87-90. [CrossRef]

8. Koga T. Fungal immunology in the skin;immune response to dermatophytes. Nippon Ishinkin Gakkai Zasshi 2009;50:151-4. [CrossRef]

9. Grover C, Khurana A. Onychomycosis:Newer insights in pathogenesis and diagnosis. Indian J Dermatol Venereol Leprol 2012;78:263-70. [CrossRef]

10. Rosenthal SA, Stritzler R, Vilafane J. Onychomycosis caused by Aspergillus fumigatus. Report of a case. Arch Dermatol 1968;97:685-7. [CrossRef]

11. Ramos A, Ussetti P, Laporta R, Lazaro MT, Sanchez- Romero I. Cutaneous aspergillosis in a lung transplant recipient. Transplant Infect Dis 2009;11:471-3. [CrossRef] 